\title{
Supply chain management concepts: literature review
}

\author{
Aziz Muysinaliyev, Sherzod Aktamov \\ School of Management, Shanghai University, China
}

\begin{abstract}
Supply chain Management has assumed a significant role in firm's performance and has attracted serious research attention over the last few years. In this paper attempt has been made to review the literature on Supply Chain Management. A literature review reveals a considerable spurt in research in theory and practice of SCM. We have presented a literature review for 29 research papers for the period between 2005 and 2011. The aim of this study was to provide an up-to-date and brief review of the SCM literature that was focused on broad areas of the SCM concept.
\end{abstract}

Key words: Supply Chain Management, Supply Chain key performance, Literature Review

\section{Introduction}

In the current competitive scenario supply chain management assumes a significant importance and calls for serious research attention, as companies are challenged with finding ways to meet ever-rising customer expectations at a manageable cost. To do so, businesses must search out which parts of their supply-chain process are not competitive, understand which customer needs are not being met, establish improvement goals, and rapidly implement necessary improvements. Previously manufacturers were the drivers of the supply chain managing the pace at which products were manufactured and distributed. Today, customers are calling the shots, and manufacturers are scrambling to meet customer demands for options/styles/ features, quick order fulfillment, and fast delivery.

In practice, supply chain based companies (e.g., Dell, Wal-Mart, Samsung, Toyota, Lenovo, Gome, etc.) have used different performance management tools to support their supply chain strategies. Monitoring and improvement of performance of a supply chain has become an increasingly complex task. A complex performance management system includes many management processes, such as identifying measures, defining targets, planning, communication, monitoring, reporting and feedback.

Manufacturing quality - a long-time competitive differentiator - is approaching parity across the board, so meeting customer's specific demands for product delivery has emerged as the next critical opportunity for competitive advantage. Companies that learn how to improve management of their supply chain will become the new success stories in the global market place. Study on Benchmarking shows significant cost differences between organizations that exhibit best-in-class performance and traditionally, Supply Chain Management (SCM) has been a melting pot of various aspects, with influences from logistics and transportation, operations management and materials and distribution management, marketing, as well as purchasing and information technology (IT). Ideally, the all encompassing philosophy of SCM embraces each of these functions to produce an overall supply chain strategy that ultimately enhances firm performance

This paper is aimed to make a literature review based on 29 randomly chosen research papers on supply chain management where each research covers different objects and features of supply chain management. There is too small amount of research papers to be reviewed, that's why there is no intention to make any recommendations on supply chain management performance or improvement, the only purpose is to make general review based on these research works which have been done during the years from 2005 to 2011 .

\section{Supply Chain Management Concept Definition}

Before making review of chosen papers there is a need to make a small discussion on definition of supply chain management itself.

SCM has been interpreted by various researchers. Based on the relatively recent development of the supply chain literature, it is not surprising that there has been much debate as to a specific SCM definition. Ganeshan and Harrison [1] has defined SCM as a network of facilities and distribution options that performs the functions of procurement of materials, transformation of these materials into intermediate and finished products, and the distribution of these finished products to customers. Lee \& Corey [2] stated that SCM consists of the integration activities taking place among a network of facilities that procure raw material, transform them into intermediate goods and then final products, \& deliver products to customers through a distribution system. Christopher [3] defined the supply chain as the network of organizations that are involved, through upstream and downstream linkages, in the different processes and activities that produce value in the form of products and services in the hands of the ultimate customer. SCM is the "strategic and systematic coordination of the 
traditional business functions and the tactics across these business functions within a particular firm and across businesses within a supply chain, for the purposes of improving the long-term performance of the individual companies and the supply chain as a whole"[4].

While the separation of supply chain activities among different companies enables specialization and economies of scale, there are many important issues and problems that need to be resolved for successful supply chain operation - this is the main purpose of SCM. [5]

\section{Best Value Supply Chains}

Most of researches are intend to find optimum solutions for operations management in today's competitive landscape and best value supply chains are the chains that are most likely to prosper within this today's competition.

Best value supply chains use strategic supply chain management in an effort to excel in terms of speed, quality, cost, and flexibility. Despite the value of this concept to modern firms, little is known about how prominent theories can help shed light on what distinguishes these chains from others and makes them exceptionally successful. [6]

Ketchen et al. [6] noted that as a relatively new concept, the notion of best value supply chains can become clearer and richer if examined from a variety of important theoretical perspectives. Authors showed implications for the best value supply chain concept offered by nine prominent theoretical perspectives: transaction cost economics, agency theory, resource dependence theory, institutional theory, game theory, network theory, social capital theory, strategic choice, and the resource-based view/knowledge based view. [6] On our own we can say that prior to elaborating on the nine theories, it is important to state that a number of other theories can also help explain supply chain phenomena (e.g., behavioral theory of the firm, punctuated equilibrium, industrial organization, contingency theory, evolutionary economics, and population ecology).

Here we would like to perform comparison analysis done by Ketchen (et al.) where he compares best value and traditional supply chains.

Table 1.

How different theoretical perspectives help to distinguish best value and traditional supply chains

\begin{tabular}{|c|c|c|}
\hline $\begin{array}{l}\text { Theoretical } \\
\text { perspective }\end{array}$ & Best value supply chains & Traditional supply chains \\
\hline \multirow{2}{*}{$\begin{array}{l}\text { Transaction cost } \\
\text { economics }\end{array}$} & $\begin{array}{l}\text { Focus on total costs, not just transaction } \\
\text { costs, as the basis of "make or buy", } \\
\text { decisions. }\end{array}$ & $\begin{array}{l}\text { Focus on transaction costs as the basis } \\
\text { of "make or buy" decisions. }\end{array}$ \\
\hline & $\begin{array}{l}\text { Short term costs play a secondary role if the } \\
\text { potential for long term, trusting relationships } \\
\text { exists }\end{array}$ & $\begin{array}{l}\text { Opportunism undermines trust; short } \\
\text { term costs are a primary consideration }\end{array}$ \\
\hline Agency theory & $\begin{array}{l}\text { Use reward structures and cultural } \\
\text { competitiveness to align members' interests } \\
\text { Potential for opportunism minimized }\end{array}$ & $\begin{array}{l}\text { Interests of supply chain members only } \\
\text { partially aligned Strong potential for } \\
\text { opportunism }\end{array}$ \\
\hline $\begin{array}{l}\text { Resource dependence } \\
\text { theory }\end{array}$ & $\begin{array}{l}\text { Supply chain members recognize that } \\
\text { dependence can create forbearance and trust }\end{array}$ & $\begin{array}{l}\text { Each member tries to avoid becoming } \\
\text { dependent on others and tries to make } \\
\text { others dependent on it }\end{array}$ \\
\hline Institutional theory & $\begin{array}{l}\text { Use industry recipes and best practices to } \\
\text { inform, but not dictate, supply chain } \\
\text { management activities }\end{array}$ & $\begin{array}{l}\text { Rely heavily on industry recipes and } \\
\text { best practices to guide supply chain } \\
\text { management activities }\end{array}$ \\
\hline Game theory & $\begin{array}{l}\text { Mutual dependence and trust overcome } \\
\text { members' temptation to pursue self-serving } \\
\text { behavior }\end{array}$ & $\begin{array}{l}\text { Some members use free riding, hold up, } \\
\text { and leakage to benefit themselves and to } \\
\text { the detriment of the chain }\end{array}$ \\
\hline Network theory & $\begin{array}{l}\text { A blend of strong and weak ties that matches } \\
\text { supply chain needs is created in order to } \\
\text { maximize supply chain performance }\end{array}$ & $\begin{array}{l}\text { Strong and weak ties formed on a case- } \\
\text { by-case basis rather than strategically }\end{array}$ \\
\hline Social capital theory & $\begin{array}{l}\text { Shared goals, values, and experiences create } \\
\text { shared sensemaking and improved } \\
\text { performance }\end{array}$ & $\begin{array}{l}\text { Mix of shared and firm-level goals, } \\
\text { values, and experiences circumscribe } \\
\text { shared sensemaking and limit } \\
\text { performance }\end{array}$ \\
\hline Strategic choice & $\begin{array}{l}\text { Strategic decisions made with concern for the } \\
\text { chain as the primary driver. This "strategic } \\
\text { supply chain management" opens the door to } \\
\text { unique blended strategies that transcend the } \\
\text { firm }\end{array}$ & $\begin{array}{l}\text { Strategic decisions made with concern } \\
\text { for the firm as the primary driver. This } \\
\text { approach constrains firms to using a } \\
\text { generic strategy such as prospector or } \\
\text { low cost leader }\end{array}$ \\
\hline $\begin{array}{l}\text { Resource-based } \\
\text { view/knowledge based } \\
\text { view }\end{array}$ & $\begin{array}{l}\text { Assume that unique resources exist at the } \\
\text { supply chain level, and that supply chains can } \\
\text { be inimitable competitive weapons }\end{array}$ & $\begin{array}{l}\text { Assume that unique resources reside } \\
\text { within firms. Supply chain management } \\
\text { is thus a tool to complement these } \\
\text { resources }\end{array}$ \\
\hline
\end{tabular}

Source: Ketchen et al., 2007 [6] 
A recent survey done by Feller et. al. [7] of the main usages of the term "value" in the economics, marketing, strategy, and operations fields indicates that the notion of a value chain may actually be a misnomer, although a widely used one. According to this analysis, only resources move along the chain of linkages between firms supplies going one way and money going the other, while value is a metaphysical perceived quality associated with the benefits that occur at the various points of exchange along the resource chain. According to this analysis, value surrounds the movement of resources - is perceptual - and accrues to both parties in a transaction, suppliers and customers.

Therefore, value chains can be thought to operate in both directions, with suppliers accruing value from the financial resources, payment terms, stability, and future order cover that their customers provide, while customers derive value from the delivered products and services.

\section{Figure 1.}

\section{A Comparison of a Value Chain with a Supply Chain}

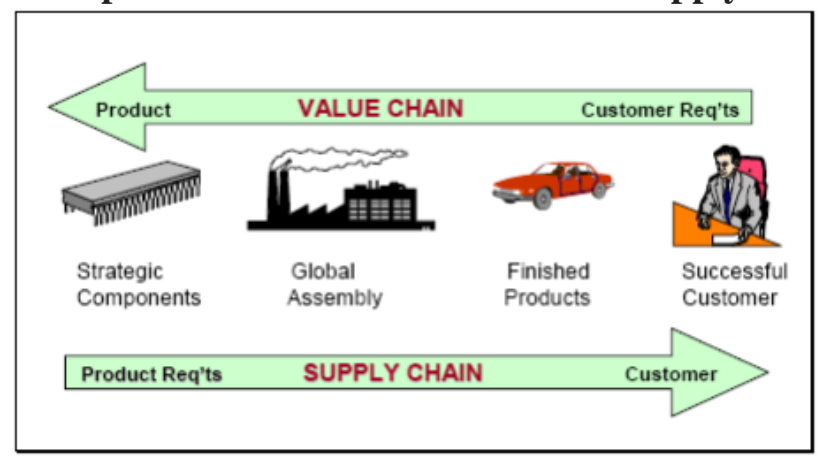

Source: Feller et al., 2006 [7]

Misnomer or not, the value chain concept has become a staple idea in the management and research literature, and is the focus for evolving strategies, enterprise models, and numerous efforts at improving business performance. Creating a profitable value chain therefore requires alignment between what the customer wants, i.e., the demand chain, and what is produced via the supply chain. And while supply chains focus primarily on reducing costs and attaining operational excellence, value chains focus more on innovation in product development and marketing. [7]

Beside of it there is research in quality management which has been done by Foster [8] has focused on internal versus external views of quality, with the internal view focusing on process and the external view focusing on the customer. As firms adopt the systems approach implicit in supply chain management, they must merge these views as they internalize upstream and downstream processes with their own.

To understand the field of supply chain quality management (SCQM), we must first define the term by deconstructing it. Bowersox et al. [9] state that supply chain management consists of firms collaborating to leverage strategic position and to improve operating efficiency. This includes partnering with other firms in chains of relationships that result in downstream benefits to customers. Similarly, the quality management perspective has traditionally considered interacting aspects of systems such as processes, inputs, machines, people, procedures, plant, and equipment as means of creating excellence in products and services. This systems-based view of quality also applies to supply chains as well. According to Fawcett et al. [10], competition now is not only found at the firm level. Business competition now exists as supply chains seek to gain advantage over competing supply chains. This level of competition requires a much greater level of coordination among chains or networks of suppliers, distributors, producers, and customers. [8]

Another issue is to keep sustainability of supply chains. The nature of the task of integrating sustainability in supply chain management is complex and tends to result in conflicts. Furthermore, where conflicts have arisen a resolution framework in supply chain management research is not yet available. The roots of supply chain management research are broadly planted in operations management and therefore the context is operations and not the environmental or social aspects, and that has not changed as it is inherent to the field. The nature of the task and context presently overcome (or 'abduct') other factors that may justify the unintentional procrastination of changing supply chain management into sustainable supply chain management. Summarizing to provoke a structural change it is essential to take into account the conflicting nature of the task and the context of supply chain management research. [11] 


\section{Evaluation And Optimization Methods Of Scm}

Still many methods and techniques have been suggested over the years for SCM evaluation. Traditional methods focus on well-known financial measures, such as the return on investment (ROI), net present value (NPV), the internal rate of return (IRR), and the payback period. These methods are best suited to measure the value of simple SCM applications. Unfortunately, evaluation methods that rely on financial measures are not well suited for newer generation of SCM applications. These complex supply chains typically seek to provide a wide range of benefits, including many that are intangible in nature.

During discussion of methods let's stop on a strategy which is a set of assumptions about cause-andeffect. If cause-and-effect relationships are not adequately reflected in the BSC, it will not translate and communicate firm's vision and strategy. These cause and-effect relationships can involve several or all four of the perspectives in the BSC framework. For example, flexibility of service systems to meet particular customer needs (internal business operations perspective) will be more likely to meet customer expectations (customer perspective). Higher level of customer expectations will lead companies to supply more innovative products and services (learning and growth perspective). This in turn will increase the market share and profitability (financial perspective). [12]

Also there is no doubt about the importance of informing in the supply chain and about the fact that information technology (especially various Internet applications) can greatly reduce the costs, strategic planning of this process and utilization of information is crucial. Information should be readily available to all companies in the supply chain and the business processes should be structured in a way to make full use of this information. The most important measures of SCM successfulness can be the final level of service, customer satisfaction and supply chain competitiveness and profitability as a whole. However as these are difficult to measure or use as a guideline to monitor improvement, more operational measurement methods and indexes were developed.

On a more operational level the key performance indicators are total costs, quality and lead times in the supply chain. Survey of performance measures showed that cost and customer responsiveness dominate as the most often mentioned measures. [5]

Cai et al [13] from other side, proposes a framework using a systematic approach to improving the iterative key performance indicators (KPIs) accomplishment in a supply chain context. The proposed research quantitatively analyzes the interdependent relationships among a set of KPIs. It can identify crucial KPI accomplishment costs and propose performance improvement strategies for decision-makers in a supply chain. In that research is provided an effective approach to managing supply chain performance in a dynamic environment. It solves the performance measures coupling problem by using a systematic approach, while few of previous research works have addressed this problem. The framework and methodology help companies improve performance across the entire supply chain in a systematic manner, through managing complex relationships among the KPIs, and refining the process of determining their KPIs. From the framework, it is feasible to get a holistic view of complex relationships among KPIs, where the cause-effect diagram becomes too complicated because of the large number of KPIs. The framework and methodology offer at least three important theoretical contributions to solve coupled KPI accomplishment problems and provide a good insight for further work. Which are as followings: first, the proposed framework provides a good implementation plan which converts the complex problem-solving into a more operational and quantitative exercise; second, the PCTM (accomplishment cost transformation matrix) analysis proposed in Cai's paper is a new extension of the existing eigenstructure analysis methods (e.g., Work Transformation Matrix - WTM - derived from the DSM model) from engineering to business performance management; third, the framework and PCTM analysis method can serve as a useful modeling tool in analyzing coupled improvement problems. Researches accept that from PCTM should not be adopted as direct decisions, but as supporting information for decision-making. Because different experts may have different opinions of critical indicators, and of different possible solutions; every expert or manager might have his own PCTM. There is no standard answer that can be accepted (and executed) unanimously. Hence, Cai declares that the final decision-making is still left to the managers. [13] 


\section{Figure 2.}

The cause-effect diagram: 20 performance indicators in the supply chain of SCC*

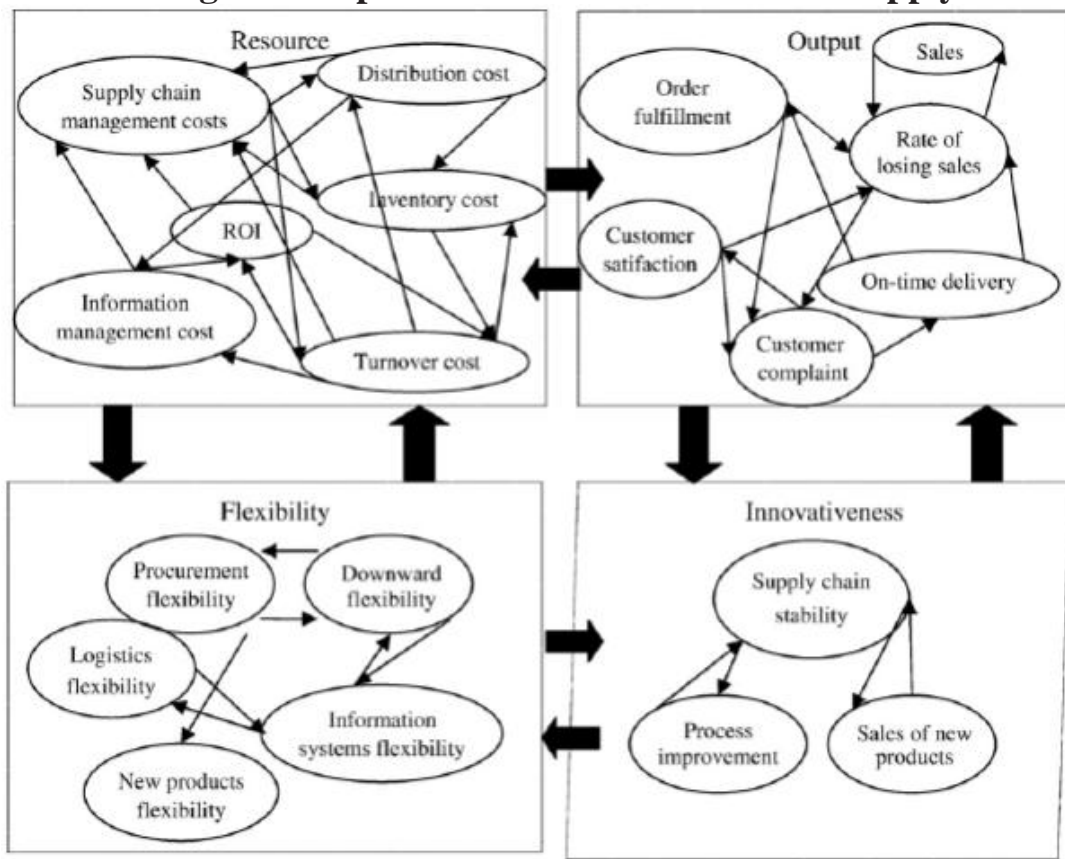

*(SC Company (SCC) has more than 800 stores in 250 cities in China, and more than 100,000 employees. It has become the biggest distributor for many electronic appliance manufactories.)

Research study of Caddy and Helou [14] addresses the question of whether the field of general systems theory could make a contribution towards a greater understanding of supply chains. Where the first principle indicates that if organizations are to have 'agile' or 'quick response' supply chains, simpler supply chains, in terms of their topology, or type and nature of the product being exchanged, should be preferred to more complex ones. The second principle indicates that organizations need to manage their supply chains on the basis of their activity, devoting more management resources to highly active ones as compared to less active ones. The third principle allows organizations to better understand their supply chains by decomposing these systems into smaller and more easily understood sub-systems. The fourth principle indicates that organizations need to accept the fact that supply chains are dynamic rather than static, and so need to focus the attention of managers at all levels on the types of changes required, and the resource implications that these changes will have on the operation of the supply chain. Regular review and change of management practice will also be necessary in order to maintain supply chain effectiveness. [14]

\section{Figure 3}

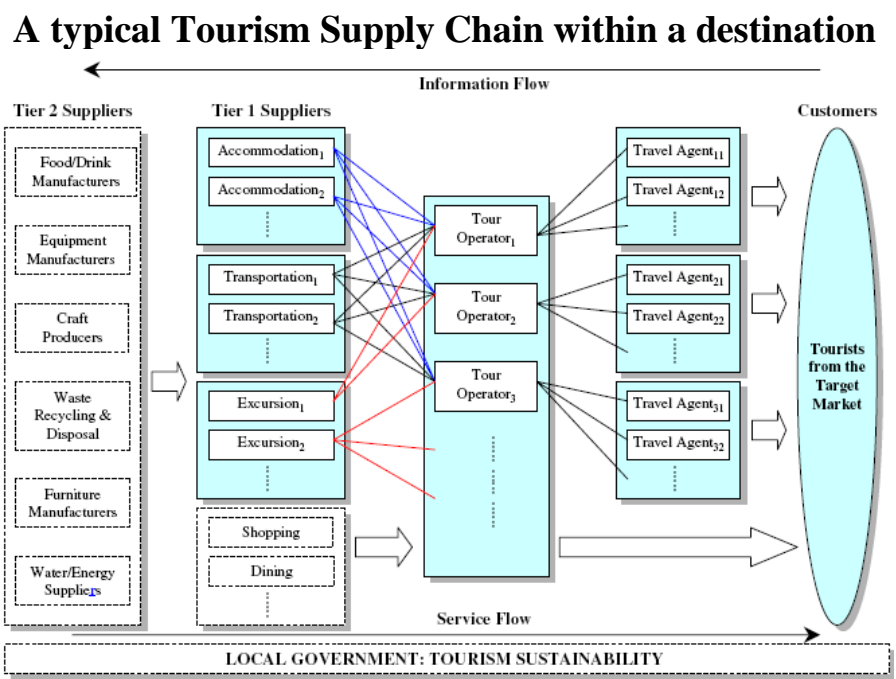


Chow et al. [15] made a try to analyze SCM in comparison of two different countries US and Taiwan and to see if methods used for optimization can be equal for any environment. Through structural equation modeling, critical components of supply chain management are found to have considerable effects on organizational performance. The findings of Chow et al. [15] are summarized as follows:

- Supply chain competencies have positive effects on organizational performance in both the US and Taiwan. Supply chain competencies are developed around quality and service, operations and distribution, and design effectiveness. The goal of supply chain competencies is to satisfy customer requirements.

- Supply chain practices, which are made up of supply chain features, integration, and customer services, have direct impact on organizational performance in Taiwan, but they have only indirect impact in the US.

- Supply chain practices and competencies are significantly associated in both the US and Taiwan. However, supply chain concerns and practices are associated in the case of the USA only.

Study shows that the practice of supply chain management may be structurally or situation-dependent. So, there may be different perceptions from country to country on how to effectively manage a supply chain. Thus, it is not the case of "one size fits all." Each country's situation may be different and would need to be understood to effectively manage the supply chain. The evidences presented in this study reinforce the notion that effective supply chain management would enable enterprises to become competitive in the new economy and significantly improve their performance. Supply chain competence has positive influence on organizational performance. Managers need to focus attention on developing such competencies.

In our opinion there can be different approach not only by countries but also by industries. Carlsson et. al [16] on his own made a quite interesting research on supply chain management on example of pulp and paper industry. Authors conclude that the pulp and paper industry depends on a long and integrated supply chain. The lead time from the first step to the last is long and it involves many steps operated by several companies and organizations. They are more focused on planning process which is one of significant aspects in chain management. Planning problems are divided into strategic, tactical and operative in a supply chain matrix and described their characteristics. They conclude that the need for information and decision support for planners in each of these areas is significant. This relates to a planning within a single company as well as integrated planning across several. [16]

While SCM studies are in most cases based on researches about manufacturing industry, there is some literature which reviews supply chain management within the context of tourism. Extensive research by Zhang et al. [17] has shown that coordination among supply chain partners in the early stage of product development benefits the successful development of new products in the era of mass customization. Recent research also shows the advantages of optimizing the product design, process design, and supply decisions in an integrated and simultaneous manner.

It is clear that the overall performance measurement of a supply chain system involves not just financial or operational measurement. Given the complexity of assessing such a flexible system, various frameworks have been proposed. As in other service industries, customer satisfaction (tourist satisfaction) is one of the most important performance measures for the tourism supply chain. Tourism researchers have investigated the measurement of overall tourist satisfaction with a particular destination and tourist satisfaction with specific service sectors, such as accommodation, restaurants, attractions, travel agencies, package tours, and retail shops.

In today's competitive environment, the sheer number of tourism service suppliers provides abundant input possibilities for tour operators to assemble tour packages, and it is believed that effective integration of suppliers with tourism product development processes could increase the competitive edge of tour operators as well as benefit the TSC as a whole.

\section{Conclusion}

In this paper the attempt has been made to review the literature on Supply Chain Management. We have presented a literature review for 29 research papers for the period between 2005 and 2011. Articles for review were chosen in random way where an only criterion for research papers was to be done after 2005. Some reviewed papers are from same category, but we did not take into consideration papers with absolutely same results. So papers can be very close in results, but there is no identical result papers included. We tried to use the discussion method in analysis of these papers and had no attempt to make any quantitative analysis, which can be used in future researches.

During selecting of research papers for literature review we used simple methods trying to select ones from different sources. The main source for using these papers was Science Direct internet portal for research papers and other Internet journals on Operations Management.

In order to have broader view on SCM we reviewed papers which have different objects, were we can divide them into such groups: (1) papers which research SCM in context of its improvement and quality, (2) papers which focus on sustainability of SC and logistics, (3) papers which based on comparison of SCs or 
comparison of implementing methods on different locations, (4) papers which look towards SCM through different industry, (5) and finally the most important number of researches are about methods of supply and efficiency of SCs, which in our opinion make greater contribution for understanding of SCM.

A literature review reveals a considerable spurt in research in theory and practice of SCM. Combining and informing on features of Supply Management and distribution Management. This integration has resulted in the concept of extended enterprise and the supply chain is now manifest as the collaborative supply chain across inter company borders to maximize the value across the entire supply chain.

During the search of papers to work on we have noticed that there is a need for some further research that we have identified as following: to conduct empirical studies about the impact of Internet on several e-SCM processes, as for example the reverse and demand management processes which, so far, have only been considered by a couple of authors. Another important area of research is the application of decision models and technologies on Internet. As more and more firms have high quality and real-time information available, the use of these decision technologies will increase, since they add significant value to the members of a supply chain. The SCM is continuously redefining itself. We also have noticed that past literature reviews provided valuable results, they were based upon the random selection of articles, book chapters and conference proceedings. [18] Other literature reviews were either more focused on operations management or examined a single journal.

The aim of this study was to provide an up-to-date and brief review of the SCM literature that was focused on broad areas of the SCM concept.

It is our hope that future researches will pay more attention on generating much needed conceptual and empirical work in the SCM literature, thereby creating a body of literature that is more heavily influenced by a deeper analysis of the supply chain on a chain wide or network basis.

\section{Acknowledgments}

This paper is done in frames of PhD studies in School of Management, Shanghai University. Thanks to all Shanghai University professors and China Government Scholarship program for foreign students.

\section{REFERENCES}

[1] Ganeshan, R, and Harrison Terry P., "An Introduction to Supply Chain Management," Department of Management Sciences and Information Systems, 1995

[2] Lee Hau L., and Corey Billington, "The Evolution of Supply-Chain-Management Models and Practice at Hewlett-Packard. Interfaces”, (25), pp. 42-63, 5 September-October, 1995

[3] Christopher M., Logistics \& supply chain management: strategies for reducing costs and improving services (Pitman Publishing, London, 1998)

[4] Mentzer J. T. , DeWitt V, Keebler K. S., Min S., Nix N. W. and Smith. C. D., Defining Supply Chain Management, Journal of Business Logistics, (22:2), 2001

[5] Trkman P., Stemberger M. I., and Jaklic J., Information Transfer in Supply Chain Management, Issues in Informing Science and Information Technology, Slovenia, 2006

[6] Ketchen Jr. David J., and Hult G. Tomas M., Bridging organization theory and supply chain management: The case of best value supply chains, Journal of Operations Management (25), pp. 573-580, 2007

[7] Feller A., Shunk D., and Callarman T., Value chains versus supply chains (BPT Trends, March, 2006)

[8] Foster Jr. S. T. Towards an understanding of supply chain quality management, Journal of Operations Management (26), pp. 461467,2008

[9] Bowersox, D., Closs, D., Cooper, M.B., Supply chain logistics management (McGraw Hill, New York, NY, 2007)

[10] Fawcett, S., Ellram, L., Ogden, J., Upper saddle river (Prentice-Hall, NJ. 2006)

[11] De Brito M. P. and. Van der Laan E. A. Supply Chain Management and Sustainability: Procrastinating Integration in Mainstream Research, Sustainability Journal, (2), pp. 859-870, 2010

[12] Bhagwat R. and Sharma Kumar M. Performance measurement of supply chain management: A balanced scorecard approach, Computers \& Industrial Engineering Journal, (53), pp. 43-62, 2007

[13] Cai J., Liu X.D., Xiao Zh.H., Liu J. Improving supply chain performance management: A systematic approach to analyzing iterative KPI accomplishment, Decision Support Systems Journal, (46), pp. 512-521, 2009

[14] Caddy I. N. and Helou M. M., Supply chains and their management: Application of general systems theory, Journal of Retailing and Consumer Services, (14), pp. 319-327, 2007

[15] Chow W. S., Madu C. N., Kuei Ch-H., Lu M. H., Lin Ch.H., Tseng H.J., Supply chain management in the US and Taiwan: An empirical study, International Journal of Management Science Omega (36), pp. 665 - 679, 2008

[16] Carlsson D., D’Amours S., Martel A., Ronnqvist M., Supply chain management in the pulp and paper industry, Working paper, DT-AM3, Universite Laval, Quebec, Canada, 2006

[17] Zhang Xinyan, Haiyan Song and George Q. Huang, Tourism supply chain management: A new research agenda, Tourism Management (30), pp. 345-358, 2009

[18] Meixell M. J. and Gargeya V. B., Global supply chain design: A literature review and critique, Transportation Research Part E (41), pp. 531-550, 2005 